\title{
A STUDY OF DEPRESSION IN DIABETES AND THE RELATION OF DEPRESSION WITH GLYCAEMIC CONTROL AND DISEASE ACCEPTANCE
}

\author{
Shynu Raju1, Ramash K2
}

1 Junior Consultant, Department of Psychiatry, Government Mental Health Centre, Kozhikode, Kerala, India. ${ }^{2}$ Assistant Professor, Department of Psychiatry, Government Medical College, Kozhikode, Kerala, India.

ABSTRACT
BACKGROUND
Presence of psychiatric illness like depression may affect diet, exercise or drug management of diabetic patients. A review of 20
studies showed $15 \%$ prevalence of depression in diabetes. Psychological factors like abnormal coping skills by avoiding negative
thoughts and feelings related to diabetes may lead to higher levels of depression, poor quality of life and poor adherence to
medication. Even though the prevalence of diabetes is high in this part of the world, studies related to above factors are rare.

\section{MATERIALS AND METHODS}

A cross-sectional study to find the prevalence of depression and its relation to blood sugar control and disease acceptance. Patients satisfying WHO criteria of diabetes, with age more than 35 and duration of diabetes less than 5 years and without having other severe physical illness or mental retardation were studied by using MINI neuropsychiatric inventory, MADRS and AADQ.

\section{RESULTS}

Among the 320 diabetic patients examined, psychiatric diagnosis was present made 122 (38.1\%) and out of this, depression was present in 64 patients (20\%). 58 patients with a psychiatric diagnosis other than depression were excluded from the analysis to avoid the confounding variables. The remaining 262 patients were analysed. Among the depressive patients, 26 (40.6\%) had mild depressive episode, 28 (43.8\%) had moderate depressive episode and 10 (15.6\%) had severe depressive episode. Out of the 38 patients in 'without dietary modification' group 22 showed depressive disorder, which is significant ( $\mathrm{p}$ value 0.000 ). Among the 14 patients with diabetic complications depression was present in 8 patients, significant relation with $\mathrm{p}$ value 0.003 . Among the 157 patients with combined treatment (both $\mathrm{OHA}$ and insulin) depression was present in 50 patients, significant relation with p value 0.003. Mean $\mathrm{HbA}_{1} \mathrm{C}$ in depressed group was 10.575 and non-depressed group was 8.641 , significant statistically with $p$ value 0.000 . Mean AADQ score in depressed group was 42.14 and in non-depressed group was 59.22. There was significant difference between the group. AADQ values had significant negative correlation with $\mathrm{HbA}_{1} \mathrm{C}$ and there was statistically significant positive correlation between $\mathrm{HbA}_{1} \mathrm{C}$ and severity of depression.

\section{CONCLUSION}

Depression is a common comorbidity in diabetes mellitus (20\%). Low acceptance of diabetes is related to depression and the severity of depression is positively correlated with $\mathrm{HbA}_{1} \mathrm{C}$ values.

\section{KEY WORDS}

Depression, Diabetes, $\mathrm{HbA}_{1} \mathrm{C}$ and Acceptance.

HOW TO CITE THIS ARTICLE: Raju S, Ramash K. A study of depression in diabetes and the relation of depression with glycaemic control and disease acceptance. J. Evolution Med. Dent. Sci. 2018;7(45):4896-4899, DOI: 10.14260/jemds/2018/1090

\section{BACKGROUND \\ Diabetes is a complex disorder in which a lot of patient's effort is needed for different aspects of its management like diet, exercise and pharmacotherapy. Psychiatric illness, especially depression will interfere with any of the above domain of diabetes management. Depressive disorder is more common in diabetic patients than in general population and depression may be a risk factor for the development of diabetes also.}

'Financial or Other Competing Interest': None.

Submission 22-09-2018, Peer Review 17-10-2018,

Acceptance 25-10-2018, Published 05-11-2018.

Corresponding Author:

Dr. Ramash $K$,

Assistant Professor,

Department of Psychiatry,

Government Medical College,

Kozhikode,

Kerala, India.

E-mail:drramashk@gmail.com

DOI: $10.14260 /$ jemds/2018/1090
Psychological stress acting through hypothalamic pituitary adrenal axis may precipitate the onset of both of these conditions and in some patients the diagnosis of diabetes itself may act as a stress for the onset of depression. A review of 20 studies on the co-morbidity of depression and diabetes found that the average prevalence was about $15 \%$, three times the rate of depressive disorders found in general adult population. ${ }^{1}$ Avoidance of negative thoughts and feelings associated with diabetes has been shown to be related to higher levels of depression, ${ }^{2}$ lower quality of life ${ }^{3}$ and lower adherence to medical regimen. ${ }^{4}$ Many newly diagnosed diabetic patients go through the typical stages of mourning. Individuals finally achieve different degrees of acceptance and inner peace. 5 Acceptance of diabetes and diabetes related cognitions are significantly related to lower $\mathrm{HbA}_{1} \mathrm{C}$ values. ${ }^{6}$ Studies on depression and related factors in diabetic patients are rare in Kerala. The present study is an attempt to investigate the psychosomatic relationship between depression and glucose control in diabetes mellitus patients and also to look into the relationship between acceptance level of the illness and glycaemic control. 


\section{Aims and Objectives}

1. To study the depressive disorder and acceptance level of diabetes as an illness in type 2 diabetic patients.

2. To study the relation between depression, blood sugar control and acceptance level.

\section{MATERIALS AND METHODS \\ Study Setting}

Study was conducted in diabetic clinic under Department of General Medicine, Medical College, Calicut from January 2012 to September 2012.

\section{Study Design}

Cross-sectional study.

\section{Inclusion Criteria}

1. Patients with diagnosis of type II diabetes mellitus by the physician and satisfying the WHO criteria for diabetes mellitus.

2. Patients who give informed consent.

3. Patients $>35$ years of age.

4. Patients with duration of diabetes $<5$ years.

\section{Exclusion Criteria}

Patients with other severe or acute physical illness or disability patients with gross mental retardation or any other medical or neurological conditions interfering with observations and recording of information.

\section{Study Tools}

1. Semi-structured proforma.

2. Mini International Neuropsychiatric Interview (MINI): It is a brief structured interview for major axis I psychiatric disorders in DSM IV and ICD 10.

3. Montgomery Asberg Depression Rating scale (MADRS). Devised by Montgomery and Asberg in 1979. It is a 10item scale to assess the severity of depressive disorder. Each item is rated on a 4-point scale. It is rated as $0-6$. No depression; 7 - 19 Mild depression; 20 - 34 Moderate depression; 35 - 60 Severe depression. It measures psychological symptoms mainly and it does not contain items for somatic or physical symptoms. Therefore, it is useful in assessing patients with concurrent physical illness.

4. Acceptance and Action Diabetic Questionnaire (AADQ). Devised by Greg et al in 2007. It is the diabetic specific version of acceptance and action questionnaire. It is a scale, which measures acceptance or psychological flexibility. AADQ measures acceptance of diabetes related thoughts and feelings and the degrees to which they interfere with valued action. It has 11 items. All items are reverse scored, except item 2. It is a selfreported scale.

\section{Study Method}

Study sample was taken from type II diabetes mellitus patients attending diabetic clinic was taken for convenience. All patients satisfying inclusion and exclusion criteria were selected for the study. Sample size of study calculated was 320 taken for convenience. Informed consent was taken from each patient. Socio-demographic and other relevant data were collected using semi-structured proforma. Then, MINI was administered and psychiatric diagnosis was made accordingly. Patients with a psychiatric diagnosis other than depressive disorder was excluded from analysis to avoid confounding variables. Severity of depression among the depressed patient group was assessed by using MADRS (Montgomery Asberg Depression Rating Scale). Acceptance level of patient was assessed using AADQ questionnaire. Single $\mathrm{HbA}_{1} \mathrm{C}$ value was obtained for each patient.

\section{Statistical Analysis}

Data analysis was done by using two-tailed Pearson correlation coefficient tests and independent t-test with help of SPSS software version 13.

\section{RESULTS}

Among the 320 diabetic patients, 124 were males and 196 were females and 292 were from rural area and only 28 were from urban area. Most of them were married (303) and living with spouse. Among these patients 176 were housewives, 96 were manual labourers, professionals and skilled workers were 35 only. 313 (97.8\%) patients belonged to low socioeconomic status and 7 (2.2\%) of middle socioeconomic status.

Psychiatric diagnosis was present in 122 (38.1\%) patients, out of which $64(20 \%)$ had depressive disorder. Eight had past history of mental illness and 19 had family history of mental illness.

\section{Diabetic Characteristics of Patients}

In the sample, 170 (53.1\%) of diabetic patients had family history of diabetes. 264 (83.4\%) patients had dietary modification. Most of the patients had mild physical activity ( $n=197 ; 61.6 \%)$ level, 110 (34.4\%) patients had moderate physical activity level and 13 (4.1\%) lead sedentary life. Diabetic complications were present in 16 (5\%) of patients, which was mainly peripheral neuropathy. Most of the patients $(n=195 ; 60.9 \%)$ were on both Oral Hypoglycaemic (OHA) and Insulin. 72 (22.5\%) patients were on Oral Hypoglycaemic alone and 53 (16.6\%) on Insulin alone.

\section{Characteristics of Patients with Comorbid Depressive Disorder}

Among the 320 diabetic patients 58 patients with a psychiatric diagnosis, other than depression were excluded from analysis to avoid confounding variables. In the remaining 262 diabetic patients, 64 patients had depressive disorder. Among the depressive disorder patients 46 (72\%) were females and 18 (28\%) were males, 26 (40.6\%) had mild depressive episode, 28 (43.8\%) had moderate depressive episode and 10 (15.6\%) had severe depressive episode.

Among the 224 patients with dietary modification, depression was present only in $18.8 \%$ (42 out of 224 ) and among 38 patients without dietary modification showed $57 \%$ (22 out of 38) of depressive disorder, which is statistically significant ( $\mathrm{p}$ value 0.000 ).

Among the 14 patients with any diabetic complications, depression was present in 8 patients (57.1\%) and among 248 patients without diabetic complications depression was present only in 26 patients $(22.6 \%)$ which is statistically significant ( $\mathrm{p}$ value 0.003 ). 
Among the 65 patients with OHA alone as treatment depression was present in 8 patients (12.3\%), among the 40 patients insulin alone. Depression was present in 6 patients (15\%) and among the 157 patients with combined treatment depression was present in 50 patients (31.8\%) which is statistically significant ( $\mathrm{p}$ value 0.003 ). Among the 7 patients with sedentary lifestyle, 6 were depressed (85.7\%). Among the 164 patients with mild physical activity depression was present in 44 patients (26.8\%) and among the 91 patients with moderate physical activity depression was present in 14 patients $(15.4 \%)$, which was statistically significant ( $\mathrm{p}$ value 0.000).

\begin{tabular}{|c|c|c|}
\hline \multirow{2}{*}{ Variable } & \multicolumn{2}{|c|}{ Depressive Disorder } \\
\cline { 2 - 3 } & Present (n=64) & Absent (n=198) \\
\hline HbA $_{1} \mathrm{C}$ & & \\
Mean & 10.575 & 8.641 \\
SD & 1.3545 & 0.8703 \\
\hline \multicolumn{2}{|c|}{ Table 1. Distribution of $\mathbf{H b A}_{\mathbf{1}}$ C and Depressive Disorder } \\
\hline
\end{tabular}

$\mathrm{P}$ value $=0.000$.

\begin{tabular}{|c|c|c|}
\hline \multirow{2}{*}{ Variable } & \multicolumn{2}{|c|}{ Depressive Disorder } \\
\cline { 2 - 3 } AADQ & Present (n=64) & Absent (n=198) \\
Mean & 42.14 & 59.22 \\
SD & 8.468 & 6.755 \\
\hline \multicolumn{2}{|c|}{ Table 2. Distribution of AADQ and Depressive Disorder }
\end{tabular}

$P$ value $=0.000$.

There was statistically significant difference between the two groups for $\mathrm{HbA}_{1} \mathrm{C}$ and $\mathrm{AADQ}$. In patients with depressive disorder, mean $\mathrm{HbA}_{1} \mathrm{C}$ value was 10.575 (SD-1.3545) and mean AADQ value was 42.14 (SD-8.468).

\begin{tabular}{|c|c|c|c|c|}
\hline & & $\mathbf{H b A}_{\mathbf{1}} \mathbf{C}$ & Age & Duration of DM \\
\hline \multirow{2}{*}{ AADQ } & $\begin{array}{c}\text { Pearson } \\
\text { Correlation }\end{array}$ & -0.920 & -0.011 & -0.227 \\
\cline { 2 - 5 } & $\begin{array}{c}\text { Significance } \\
\text { (2-tailed) }\end{array}$ & 0.000 & 0.850 & 0.000 \\
\hline
\end{tabular}

Table 3. Correlation between AADQ and other Variables

AADQ had negative correlation with $\mathrm{HbA}_{1} \mathrm{C}$, which was found to be statistically significant. AADQ had negative correlation with age and duration of diabetes.

\begin{tabular}{|c|c|c|c|c|}
\hline & & AADQ & Age & Duration of DM \\
\hline \multirow{2}{*}{$\mathrm{HbA}_{1} \mathrm{C}$} & $\begin{array}{c}\text { Pearson } \\
\text { Correlation }\end{array}$ & -0.920 & 0.029 & 0.248 \\
\cline { 2 - 5 } & $\begin{array}{c}\text { Significance } \\
\text { (2-tailed) }\end{array}$ & 0.000 & 0.608 & 0.000 \\
\hline \multicolumn{4}{|c|}{ Table 4. Correlation between HbA $_{1}$ C and other Variables } \\
\hline
\end{tabular}

$\mathrm{HbA}_{1} \mathrm{C}$ had negative correlation with AADQ (statistically significant) and positive correlation with age and duration of diabetes.

\begin{tabular}{|c|c|c|}
\hline & & MADRS \\
\hline \multirow{2}{*}{$\mathrm{HbA}_{1} \mathrm{C}$} & Pearson correlation & 0.693 \\
\cline { 2 - 3 } & Significance(2-tailed) & 0.000 \\
\hline \multicolumn{2}{|c|}{ Table 5. Correlation between HbA $_{1}$ C and MADRS } \\
\hline
\end{tabular}

There was positive correlation between $\mathrm{HbA}_{1} \mathrm{C}$ and severity of depression (assessed using MADRS), which was found to be statistically significant.

\section{DISCUSSION}

In this study the prevalence of clinical depression among diabetes patients were $20 \%$, which comes in the range of the chance of depression $(8.5 \%-27.3 \%)$ in a systematic review of 20 studies by Gavard et al. ${ }^{7}$ These rates are at least two times the prevalence of major depressive disorder found in the general adult population of the US. A meta-analysis of 39 studies on the prevalence of co-morbid depression in adults with diabetes concluded that diabetes doubles the odds of depression. ${ }^{8}$ In the above meta-analysis, the male-female distribution among depressed patients were exactly same in the present study (18\% and $28 \%)$.

In the group with depression, 42 patients had dietary modification and 22 patients did not modify their diet. It was also found that patients who led a sedentary lifestyle were more in the group of patients with depression than in the group without depression. The difference in the physical activity level was significant between the two groups. Clinical management guidelines of diabetes emphasise the importance of medication adherence, physical activity, diet and self-monitoring of blood glucose. ${ }^{9}$ Gonzalez et al proposed that the presence of depressive symptoms are good predictors of poor adherence to self-care, particularly in adherence to medications and diet and exercise regimens. ${ }^{10}$

Mean $\mathrm{HbA}_{1} \mathrm{C}$ in the group with depression was 10.575 and that in the group without psychiatric diagnosis was 8.641. This finding was statistically significant with a $p$ value of 0.000 . This study found positive correlation between $\mathrm{HbA}_{1} \mathrm{C}$ and severity of depression, which was assessed by MADRS. A meta-analysis by Lustman et al have determined an association between depression and hyperglycaemia. The increase in glycosylated haemoglobin levels attributed to depression alone has ranged from $1.8-3.3 \% .^{11}$ The findings in the current study is similar to these studies regarding the relation between depression and hyperglycaemia. A study by Marcelo Papelbaum et al showed higher levels of glycated haemoglobin $(8.6 \pm 2.0$ vs $7.5 \pm 1.8 ; \mathrm{p}=0.05)$ when compared to those who did not exhibit a mood disorder.12 In another study data on 11,525 veterans with type 2 diabetes were analysed. Unadjusted mean $\mathrm{HbA}_{1} \mathrm{C}$ values were significantly higher in depressed vs non-depressed subjects at all time points. ${ }^{13}$

In the present study $57 \%$ patients with complications of diabetes had depressive disorder also, which is statistically significant p-value 0.003. In the same line, de Groot et al, conducted a meta-analysis examining the association between depression and diabetes outcomes. Twenty-seven studies were included and the authors found a significant association between depression and clinical complications of diabetes ( $\mathrm{p}<0.00001 ; \mathrm{z}=5.94) .14$

Many newly diagnosed diabetics go through the typical stages of mourning. These are denial, anger, depression and acceptance. Individuals achieve different degrees of acceptance and inner peace. Some will need to experience the denial, anger and depression several times as they move through different phases of life and different stages of diabetes. Some people move through a chronic disease to a state of much greater self-knowledge. They may actually say 
that the diabetes was in part a blessing. Through their close attention to diet and exercise, and their close monitoring of stress levels, they have arrived at a deeper understanding of themselves and their relations to others. They realize that for all human beings, life is vulnerable and precious. 15

The mean Acceptance Action Diabetic Questionnaire (AADQ) score in patients with depression was 42.14 against 59.22 in patients without depression. This finding was statistically significant with $\mathrm{p}$ value of 0.000 . In this study significant negative correlation was found between AADQ score and $\mathrm{HbA}_{1} \mathrm{C}$ in the whole sample. Gregg et al applied Acceptance and Commitment Therapy (ACT), which teaches individuals to accept their feelings, to "diffuse" or disengage from the content of their thoughts by focusing more mindfully on the process of thinking itself and to link all of these to goal-based action. Self-management and hence $\mathrm{HbA}_{1} \mathrm{C}$ improved significantly in the therapy group. ${ }^{16}$ A study by Anette Richardson found that persons with a high degree of acceptance of IDDM had a high coping capability, better metabolic control, lower $\mathrm{HbA}_{1} \mathrm{C}$ and less disease related complications. They concluded that it is important to individualise the care of subjects with IDDM and to identify the persons with low acceptance of their disease and a low sense of coherence. ${ }^{6}$

\section{Limitations}

- The study was conducted in a speciality clinic in a tertiary care centre and hence the sample is not representative of type 2 diabetic patients in general population.

- $\quad$ The strict diagnostic criteria used in the study may result in exclusion of subsyndromal depressive symptoms and dysthymia.

- This is not a prospective study. Only follow-up of patients can clearly establish the relationship between depression, acceptance level and glycaemic control.

\section{CONCLUSION}

- Depressive disorder was present in $20 \%$ of type 2 diabetic patients.

- Acceptance level was low in patients with depressive disorders.

- Glycaemic control was low in patients with depressive disorder compared to patients without depression.

- $\mathrm{HbA}_{1} \mathrm{C}$ value of patients and severity of depression showed positive correlation.

There was negative correlation between acceptance level (Assessed by AADQ score) and glycaemic control $\left(\mathrm{HbA}_{1} \mathrm{C}\right)$ in the whole sample.

\section{REFERENCES}

[1] Anderson RJ, Freedland KE, Clouse RE, et al. The prevalence of comorbid depression in adults with diabetes: a meta-analysis. Diabetes Care 2001;24(6):1069-78.

[2] Boey KW. Adaptation to type II diabetes mellitus: depression and related factors. International Medical Journal 1999;6(2):125-32.

[3] Coelho R, Amorim I, Prata J. Coping styles and quality of life in patients with non-insulin-dependent diabetes mellitus. Psychosomatics 2003;44(4):312-8.

[4] Weijman I, Ros WJ, Rutten GE, et al. The role of work related and personal factors in diabetes selfmanagement. Patient Educ Couns 2005;59(1):87-96.

[5] Watkins C. Diabetes depression and stress. Northern Country of Psychiatric Associates 2007:410-329-2028.

[6] Richardson A, Adner N, Nordstrom G. Persons with insulin dependent diabetes mellitus: acceptance and coping ability. Journal of Advanced Nursing 2001;33(6):758-63.

[7] Gavard JA, Lustman PJ, Clouse RE. Prevalence of depression in adults with diabetes. An epidemiological evaluation. Diabetes Care 1993;16(8):1167-78.

[8] Raval A, Dhanaraj E, Bhansali A, et al. Prevalence and determinants of depression in type 2 diabetes patients in a tertiary care centre. Indian J Med Res 2010;132:195-200.

[9] Egede LE. Effect of depression on self-management behaviors and health outcomes in adults with type 2 diabetes. Curr Diabetes Rev 2005;1(3):235-43.

[10] Gonzalez S, Safren SA, Delahanty LM, et al. Symptoms of depression prospectively predict poorer self-care in patients with type 2 diabetes. Diabet Med 2008;25(9):1102-7.

[11] Lustman PJ, Anderson RJ, Freedland KE, et al. Depression and poor glycemic control: a meta-analytic review of literature. Diabetes Care 2000;23(7):934-42.

[12] Papelbaum M, Moreira RO, Coutinho W, et al. Depression, glycemic control and type 2 diabetes. Diabetol Metab Syndr 2011;3(1):26.

[13] Richardson LK, Egede, LE, Mueller M, et al. Longitudinal effects of depression on glycemic control in veterans with type 2 diabetes. Gen Hosp Psychiatry 2008;30(6):509-14.

[14] de Groot M, Anderson R, Freedland KE, et al. Association of depression and diabetes complications: a meta-analysis. Psychosom Med 2001;63(4):619-30.

[15] Watkins C. Diabetes, depression and stress. Northern County Psychiatric Associates 2004:410-329-2028.

[16] Gregg JA, Callaghan GM, Hayes SC, et al. Improving diabetes self-management through acceptance, mindfulness, and values: a randomised controlled trial. J Consult Clin Psychol 2007;75(2):336-43. 